\title{
Influence of Si on the Structural, Electrical, and Optical Properties of (Al, Ti, Si)N Films Deposited Via Reactive DC Sputtering
}

\author{
A.M. Guzman Palacios ${ }^{a}$, J.J. Olaya ${ }^{a}$ (D, J.E. Alfonso ${ }^{b *}$ (D) \\ ${ }^{a}$ Universidad Nacional de Colombia, Facultad de Ingeniería, Bogota, Colombia \\ ${ }^{b}$ Universidad Nacional de Colombia, Departamento de Física, Grupo de Ciencia de Materiales y \\ Superficies, Bogota, Colombia
}

Received: December 20, 2019; Revised: September 28, 2020; Accepted: October 16, 2020

\begin{abstract}
The physical and chemical properties of multifunctional materials have been extensively studied in the last few years especially the mechanical and tribological applications and less attention has taken the electrical and optical properties. Therefore, in this work presents the growth of (Al, Ti, Si)N films deposited on common glass substrates with a maximum thickness of $1024 \mathrm{~nm}$, via reactive DC magnetron sputtering, to analyze the influence of the silicon content on their crystallographic structure, optic and electric behavior. The microstructure of the films was characterized by X-ray diffraction (XRD). The films morphology was evaluated through scanning electronic microscopy (SEM). The optical measurements were carried out by means UV-vis spectroscopy, and the electrical properties were analyzed using a four-point probe. XRD analysis indicated that the films changed from a crystalline phase to an amorphous phase, and the electrical and optical response indicated that the films with higher Si content have $1223.6 \Omega . \mathrm{cm}$ of resistivity with an energy gap of approximately $1.0 \mathrm{eV}$ and an optical energy gap of $1.5 \mathrm{eV}$. This electrical property has not been previously reported in these films.
\end{abstract}

Keywords: Multifunctional, films, sputtering, optical and electrical properties.

\section{Introduction}

Ceramic films of transition metal nitrides grown via Physical Vapor Deposition (PVD) have been widely used in various engineering applications. Specifically, (Ti,Al,Si)N nanostructured coatings have been attracted a lot of attention given their metallic nature associated with an fcc-TiN, along with their dielectric behavior of AlN in the wurtzite crystal structure, and amorphous silicon nitride- $\alpha-\mathrm{Si}_{3} \mathrm{~N}_{4}{ }^{1-3}$. Additionally, these materials have been used for several industrial applications as protective coatings for tooling and cutting operations ${ }^{4-7}$, in diffusion barrier coatings in energy devices $^{6}$, and in spectrally selective solar absorbers, where TiN and (Ti,Al)N are chemically inert and have spectral and protective selectivity against corrosion ${ }^{8-13}$.

The composites with TiN that have a resistivity under of $10 \Omega-m$ are part of the conductive ceramics that are used for electrical discharge equipment ${ }^{14}$. The electrical resistivity in these composites depend primarily on the content of the TiN phase and on the microstructure formed during its production ${ }^{15}$. For example, the electrical conductivity of $\mathrm{Si}_{3} \mathrm{~N}_{4}-\mathrm{TiN}$ presents a percolation behavior, which is characterized by a decrease in resistivity for low content of $\mathrm{TiN}^{16}$. The concentration of TiN that enables the formation of a conductive network is called percolation threshold ${ }^{17}$. This behavior may be regarded as a second-order phase transformation. Lux describes the models for the evaluation of the percolate behavior, in mixtures with a high insulating matrix and dispersed conductive phase ${ }^{18}$. Apart from the electrical conductivity,

*e-mail: jealfonsoo@unal.edu.co many of the properties of the materials show a large range of values at or near the percolation threshold ${ }^{19}$.

On the other hand, in recent work the addition of a third element, in small quantities, to the crystallographic lattice of metal nitrides has modified its crystallographic structure, determining changes in the chemical-physical properties of these nitrides. A chemical element that has been widely used is silicon $(\mathrm{Si})^{20-23}$. The addition of this element to the nitride atomic lattice has shown that it affects the morphology, microstructure and functional properties of the coating due to the formation of a nanocomposite structure, which consists of two phases, a nanocrystalline and another amorphous ${ }^{24}$. These materials have been shown to have a combination of excellent mechanical properties (high hardness and fracture toughness), high thermal stability, high oxidation resistance, high corrosion resistance and good tribological properties (friction coefficients between 0.5 to 0.7 ) compared to transition metal nitrides ${ }^{25,26}$. However, there are few works that study the optical and electrical behavior of films ( $\mathrm{Ti}$, $\mathrm{Al}, \mathrm{N}) \mathrm{Si}$. Therefore, in this work, (Al,Ti,Si)N films were grown via reactive DC magnetron sputtering, and their electrical and optical properties were evaluated as a function of their Si content.

\section{Experimental Method}

The films were grown via reactive DC sputtering technique from a TiAl (Ti50\%-A150\%), Plasmaterial.INC target. In this target were placed one and two quadrangular $\mathrm{Si}{ }_{\text {pieces }}$ of $0.508 \mathrm{~cm}^{2}$. The deposition conditions of the films 
were: initial pressure of $5 \times 10^{-6} \mathrm{mbar}$ and the final pressure of $3.46 \times 10^{-4}$ mbar (Ar+N2 pressures), the power applied to the target was fixed at $200 \mathrm{~W}$ (current density of $9.34 \mathrm{~mA} . \mathrm{cm}^{-2}$ ). The distance between the target and the glass substrate $(1 \mathrm{~cm} \mathrm{x}$ $1.5 \mathrm{~cm}$ ) was kept constant in $5 \mathrm{~cm}$, the substrate temperature was $150^{\circ} \mathrm{C}$ (measured with $\mathrm{K}$-type thermocouple), and time deposition was of one hour. In Table 1 is summarize this deposit conditions.

The morphological characterization was performed with a FEI Quanta 200 scanning electron microscope equipped with an energy dispersive X-ray (EDX) probe. The X-ray diffraction (XRD) patterns were registered with Phillips $\mathrm{X}$-Pert Pro Panalytical equipment, working in Bragg-Brentano $(\theta-2 \theta)$ configuration and $\mathrm{Cu} \mathrm{K} \alpha$ radiation $(\lambda=1.540998 \AA)$. $\mathrm{XRD}$ patterns were taken for a $2 \theta$ range between 10 and $90^{\circ}$ in steps of $\Delta 2 \theta=0.02$, and a Cary Varian 5000 UV-VIS-NIR spectrophotometer was used to study the optical properties of the films. The transmittance measurements were made from 200 to $2.500 \mathrm{~nm}$ wavelength range and the electrical measurements were made using four-point equipment, varying DC voltage between -20 to $20 \mathrm{~V}$. The measure the thickness of the film was carried out with a Bruker Contour GT-K 3D optical microscope.

\section{Results and Discussion}

Figure 1 shows scanning electronic microscopy (SEM) micrographs of (A1,Ti,Si)N film surfaces and their transversal sections. The morphology of the surfaces of films deposited without Si and with one Si piece is smooth and no evident droplets or porosities. This morphology is typical of the films deposited with sputtering technique. On the surface of the films, that grew with two Si pieces have droplets with different radius. Moreover, the transversal sections that show in figures $b$ and $d$ indicate that the growth mechanism is columnar, while the film growth with more Si presents a coalescence mechanism growth.

Representative EDX spectrum of the (Al, Ti, Si)N films is shown in Figure 2. In this spectrum is evident the presence of lines Ka of X-ray of N (392.40 ev), Al (1.48 keV), Si (1.73) and $\mathrm{Ti}(4.51 \mathrm{Kev})$. Additionally, appear X-ray lines of the glass substrate. Table 2 shows the composition of (Al,Ti,Si)N films that were deposited on glass substrates and analyzed by means EDX. The analysis shows that the

Table 1. Deposition conditions of the (Ti, Al, N) Si films.

\begin{tabular}{cc}
\hline Deposit Parameters. & \\
\hline Initial pressure (mbar) & $5 \times 10^{-6}$ \\
\hline Final pressure $(\mathrm{mbar})$ & $3.46 \times 10^{-4}$ \\
\hline Power $(\mathrm{W})$ & 200 \\
\hline Current density $\left(\mathrm{mA} / \mathrm{cm}^{2}\right)$ & 9.34 \\
\hline Substrate Temperature $\left({ }^{\circ} \mathrm{C}\right)$ & 150 \\
\hline Deposition Time $(\mathrm{h})$ & 1 \\
\hline
\end{tabular}

atomic percentage of $\mathrm{Si}$ increases and that of $\mathrm{Al}$ decreases in the films. The difference in composition could be attributed to the different sputtering yields ( 0.33 for $\mathrm{Al}, 0.18$ for $\mathrm{Si}$ and 0.15 for $\mathrm{Ti}$, values calculate for ions energies of $200 \mathrm{eV}$ ). The contents of $\mathrm{Ti}$ and $\mathrm{N}$ maintain a relative stable value of $11 \pm 1$ at. $\%$ and $49 \pm 1$ at. $\%$, respectively. The values of the atomic percentage of Nitrogen make it possible to establish that the chemical composition of the films is formed by mixed TiN, AlN, and SiN phases. A considerable amount of residual oxygen $(\approx 4.0$ at. $\%$ ) were detected in all coatings, which may be due to the surface contamination of the targets when the deposition chamber was brought to air for sample transfer.

Figure 3, shows the XRD patterns from $(\mathrm{Al}, \mathrm{Ti}, \mathrm{Si}) \mathrm{N}$ films deposited on a common glass substrates at $150^{\circ} \mathrm{C}$. The peak observed at $2 \theta=33.7^{\circ}$ was index with a w-AlN phase with the space group $P 6_{3} m c$ (ICDD-00-046-1200). The dotted line in the XRD patterns indicates the position of (1010) reflections for AIN with a formation energy of $-1.595 \mathrm{eV}^{27}$. However, the slightly shifted peak position could be attributed to a substitution from $\mathrm{Ti}$ to $\mathrm{Al}$ and residual stresses in the films. In lower formation energies, it is possible to obtain an arrangement of atoms in a larger metal sub-lattice (the so-called "special quasi-random structure" or SQS); this structure has been found in TiAlN films ${ }^{28}$. When Al contents exceed the solubility limit (for molar fraction AIN $>0.70$ ), resulting in a dual phase structure of $\mathrm{c} / \mathrm{w}-\mathrm{Ti}_{1-\mathrm{x}} \mathrm{Al}_{\mathrm{x}} \mathrm{N}^{29}$. The XRD patterns for films with one piece of $\mathrm{Si}($ at.\% 3.49) have two peaks: the $w$-AlN phase (peak at $2 \theta=33.06^{\circ}$ ), and the $(\mathrm{Al}, \mathrm{Ti}, \mathrm{Si}) \mathrm{N}$, rock-salt B1 structure with the space group $\mathrm{Fm} \overline{3} \mathrm{~m}$, in solid solution (peak at $2 \theta=36.6^{\circ}(\mathrm{ICDD}-37-1140)$ ). The difference in the orientation of the peaks can result from the addition of silicon and the formation of amorphous $\mathrm{Si}_{3} \mathrm{~N}_{4}$. The silicon in the $(\mathrm{Al}, \mathrm{Ti}) \mathrm{N}$ film refined the grains and consequently increased the strain energy. When the number of atoms in a grain is reduced, an excess of surface free energy is generated $^{30}$. This grain can reduce this excess free energy by changing its preferential orientation to one that has less surface free energy ${ }^{31}$. The diminution of the crystallite size or defects caused by strain between substrate and film can lead to peak broadening ${ }^{30}$.

In XRD patterns, no peaks corresponding to $\mathrm{Si}_{3} \mathrm{~N}_{4}$ or Ti-Si compounds, suggesting that Si can be incorporated to either $\mathrm{Ti} / \mathrm{Al}$ in the c/w-TiSiAlN nano-crystallites or in amorphous $\mathrm{Si}-\mathrm{N}$ accumulated at the $(\mathrm{Ti}, \mathrm{Al}) \mathrm{N}$ nano-crystallites. These results are in accordance with those found by Chen et al. ${ }^{8}$, who reported a solid solution of Si substitution for $\mathrm{Al}$; in w-AlN and the nanocomposite, structure of nc-TiAlN $/ \alpha-\mathrm{Si}_{3} \mathrm{~N}_{4}$ has been widely accepted ${ }^{32}$. Finally, the films growing with two Si pieces have a broad and low-intensity hump, ranging from $2 \theta \sim 20$ to $30^{\circ}$, which indicates an amorphous phase (see Figure 3). These results are agreement with Yu et al. work ${ }^{33}$, who found that with the increasing of Si content, segregation of TiAlN nanocrystals in an amorphous $\mathrm{Si}_{3} \mathrm{~N}_{4}$ matrix led

Table 2. Compositions of the (A1,Ti,Si) N films (at.\%) analyzed by EDX.

\begin{tabular}{cccccc}
\hline & Ti (at.\%) & Al (at.\%) & Si (at.\%) & N (at.\%) & O (at.\%) \\
\hline TiAlN & 10.9 & 35.2 & 0.8 (substrate) & 48.8 & 4.3 \\
\hline TiAlN $+1 S i$ & 13.2 & 31.8 & 3.4 & 48.4 & 3.2 \\
\hline TiAlN $+2 S i$ & 10.4 & 28.9 & 6.0 & 50.2 & 4.5 \\
\hline
\end{tabular}




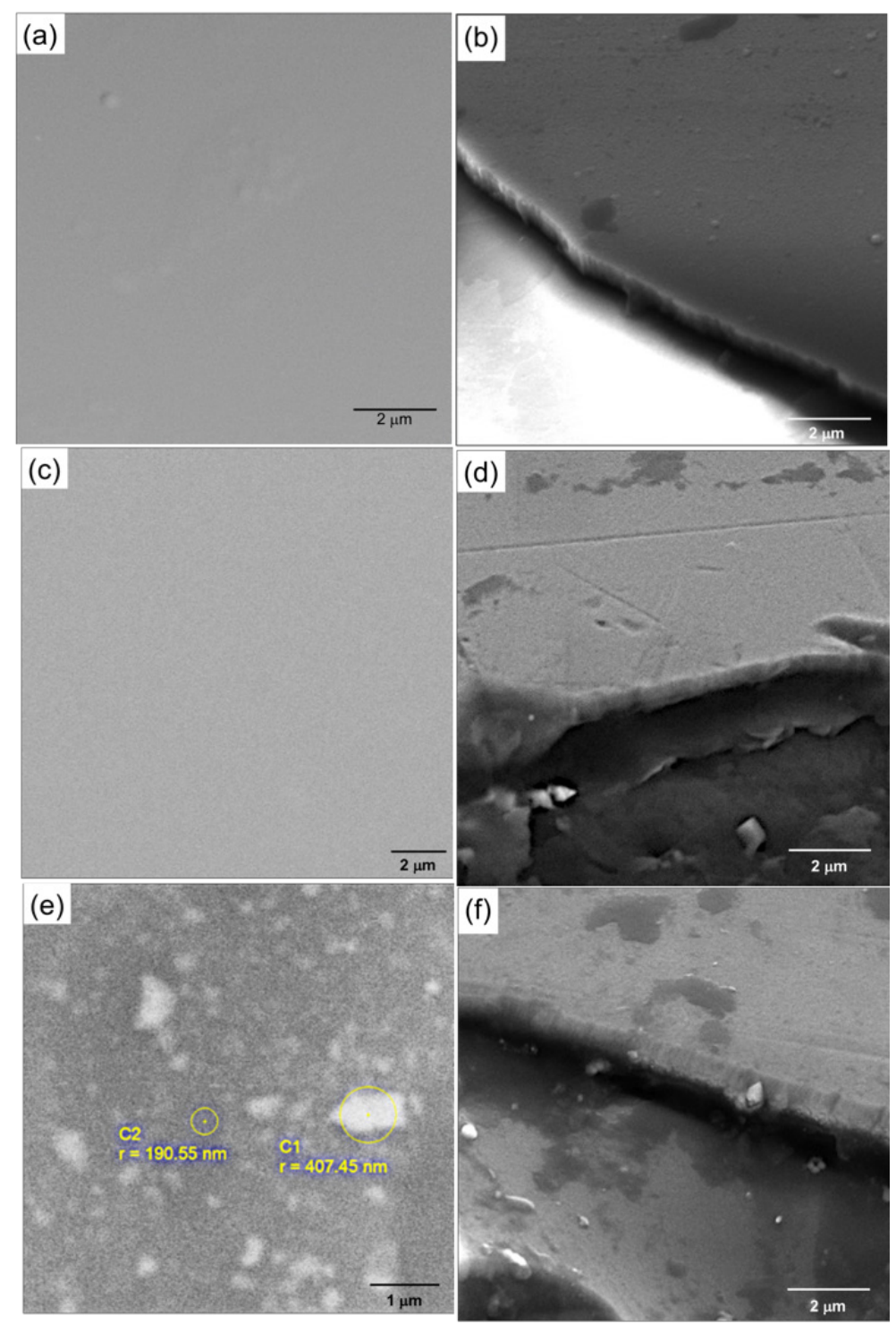

Figure 1. SEM micrograph of the (Al, Ti,Si)N film surface and transverse sections deposited on common glass (a) and (b) Without Si, (c) and (d) with one Si piece, and (e) and (f) with two Si pieces.

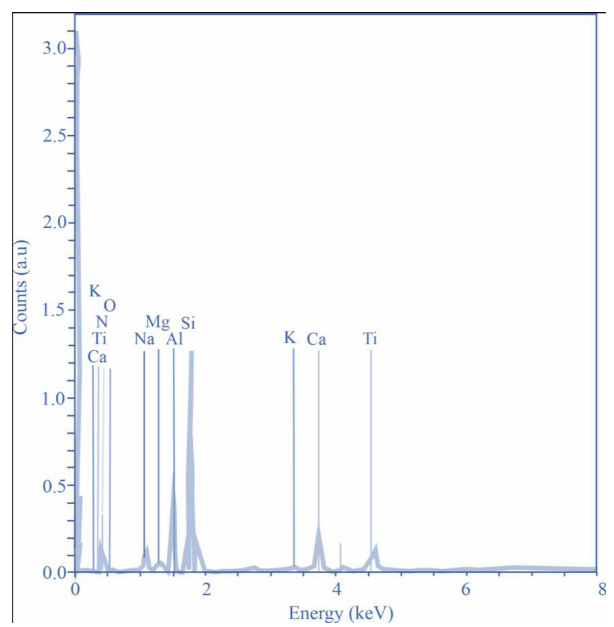

Figure 2. EDX spectrum of ( $\mathrm{Al}, \mathrm{Ti}, \mathrm{Si}) \mathrm{N}$ films deposited on glass substrate. to the formation of a composition of a mixture of the solid solution $\mathrm{Ti}(\mathrm{AlSi}) \mathrm{N}$ and $\mathrm{Ti}(\mathrm{AlSi}) \mathrm{N} / \alpha-\mathrm{Si}_{3} \mathrm{~N}_{4}$. Additionally, determined that coatings deposited with $7.95 \mathrm{Si}$ At $\%$, loss the crystallinity and coatings with 22 at.\% of Si be amorphized.

Figure 4 shows an example that how was measured of the cross section using an optical microscopy image of (Ti,Al,Si) $\mathrm{N}$ coating and Table 3 summarizes the mean thickness of the films. The thickness of the films increases from 639 to $1024 \mathrm{~nm}$. When the film grows from two-silicon pieces, the thickness drops to $953 \mathrm{~nm}$, possibly due to the development of amorphous morphology features ${ }^{33}$. Growth rates of deposition were also calculated by using deposition time.

I-V characteristics curves of the (A1,Ti,Si)N films grown on common glass are shown in Figures $5 \mathrm{a}$ and $5 \mathrm{~b}$. These figures show ohmic behavior of the films, while Figure 5c shows that films deposited with a higher Si content have the electrical behavior of a semiconductor. The electrical resistivity of (Al,Ti)N was $12.551 \Omega$.cm (see Figure 5a). By adding one 
Table 3. Thickness of (AlTiSi) $\mathrm{N}$ films with different contents of Silicon.

\begin{tabular}{ccc}
\hline & Thickness $(\mathrm{nm})$ & $\begin{array}{c}\text { Growth rate } \\
\text { (nm/min) }\end{array}$ \\
\hline TiAlN & 639 & 10.6 \\
\hline TiAlN $-1 \mathrm{Si}$ & 1024 & 17.1 \\
\hline TiAlN $-2 \mathrm{Si}$ & 953 & 15.1 \\
\hline
\end{tabular}

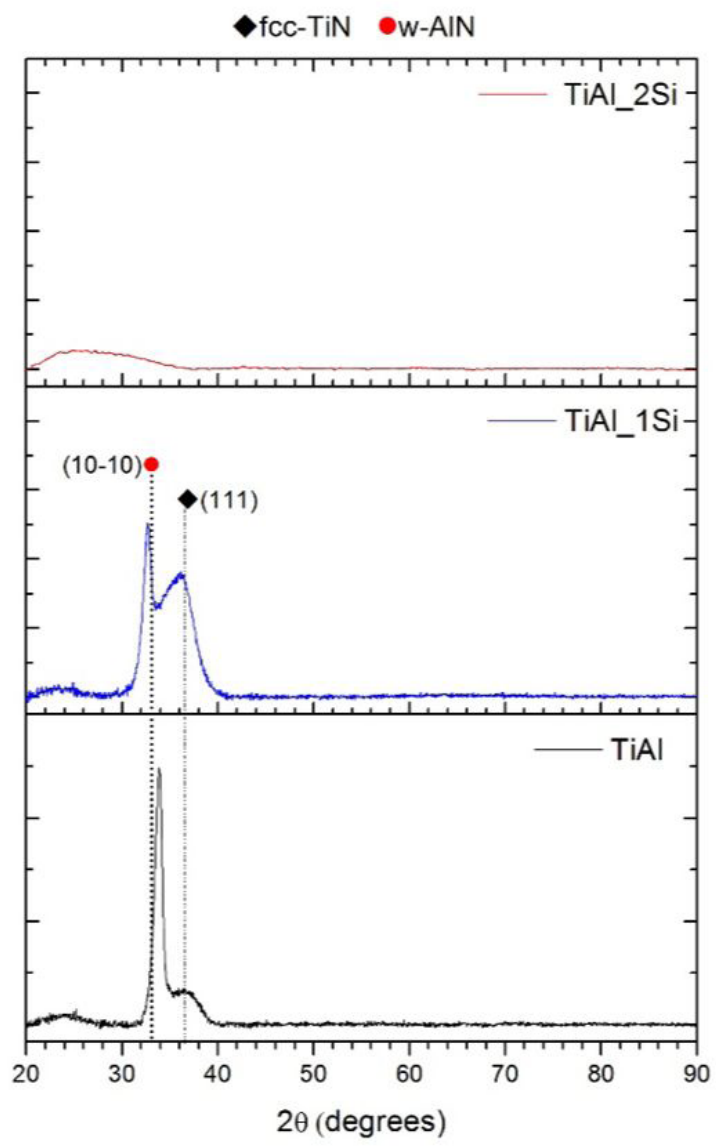

Figure 3. XRD patterns of $(\mathrm{Al}, \mathrm{Ti}, \mathrm{Si}) \mathrm{N}$ films with varying silicon contents. silicon piece into $(\mathrm{Al}, \mathrm{Ti}) \mathrm{N}$, the electrical resistivity of films drops to about $223.6 \Omega$.cm (see Figure 4 b). It is reasonable to consider that the electrical resistivity of $(\mathrm{Al}, \mathrm{Ti}) \mathrm{N}$ films somewhat increased upon adding AIN to TiN, because AlN is a well-known insulating material with a very high electrical resistivity $\left(10^{15} \Omega \mathrm{cm}\right)^{26}$. Another reason for this electrical behavior is possibly the microstructural variations in $(\mathrm{Al}, \mathrm{Ti}) \mathrm{N}$ and $(\mathrm{Al}, \mathrm{Ti}) \mathrm{N}+1 \mathrm{Si}$ films. Electrical resistivity could depend on the connectivity of the $\mathrm{c}-(\mathrm{Al}, \mathrm{Ti}, \mathrm{Si}) \mathrm{N}$ phase mixtures throughout the composite and the concentration of $\mathrm{w}-(\mathrm{Al}, \mathrm{Si}) \mathrm{N}$ and possibly $\alpha-\mathrm{Si}_{3} \mathrm{~N}_{4}$ (isolate material), so the so-called percolate behavior described by Lux ${ }^{18}$ occurs.

The energy gap of $1.0 \mathrm{eV}$ determined the semiconductor behavior of the film, with more Si content (see Figure 5c), which can be related to conduction jumps among the different potential barriers produced by the crystallites of c-(Ti, Al, Si) N and the intrinsic defects of the films that separate these metallic domains. These defects cause strong changes in the electronic structure and metal-semiconductor transitions, resulting in a hopping process in the transport of electrical charge ${ }^{34}$.

Figure 6a shows the transmittance behavior of the (Al,Ti,Si)N film as a function of the wavelength and as a study parameter, the $\mathrm{Si}$ amount. The figure shows that the films begins to have transmittance at about $300 \mathrm{~nm}$ and reaches $70 \%$ at 2,500 $\mathrm{nm}$ in films that were grown without $\mathrm{Si}$, whereas the transmittance percentage drops to approximately $10 \%$ in films that were grown with two pieces of $\mathrm{Si}$, at the same wavelength. These results show that the addition of $\mathrm{Si}$ to $(\mathrm{Al}, \mathrm{Ti}) \mathrm{N}$ films produces opacity in them ${ }^{35}$, which may occur because the films observed in SEM micrographs have homogeneity, suggesting high optical density. The transmittance behavior of the films deposited without Si corresponds with the results of other studies ${ }^{3,11,31}$. However, introducing Si into the (Al, Ti) $\mathrm{N}$ matrix could produce optic absorption across the entire electromagnetic spectrum. In a defect-free crystalline semiconductor, the absorption spectrum edge terminates at the energy gap. In contrast, in an amorphous semiconductor, a tail encroaches in the absorption spectrum into the gap region. This tail arises because the crystallographic disorder of amorphous semiconductors makes the absorption edge of these semiconductors difficult to define experimentally ${ }^{36}$.

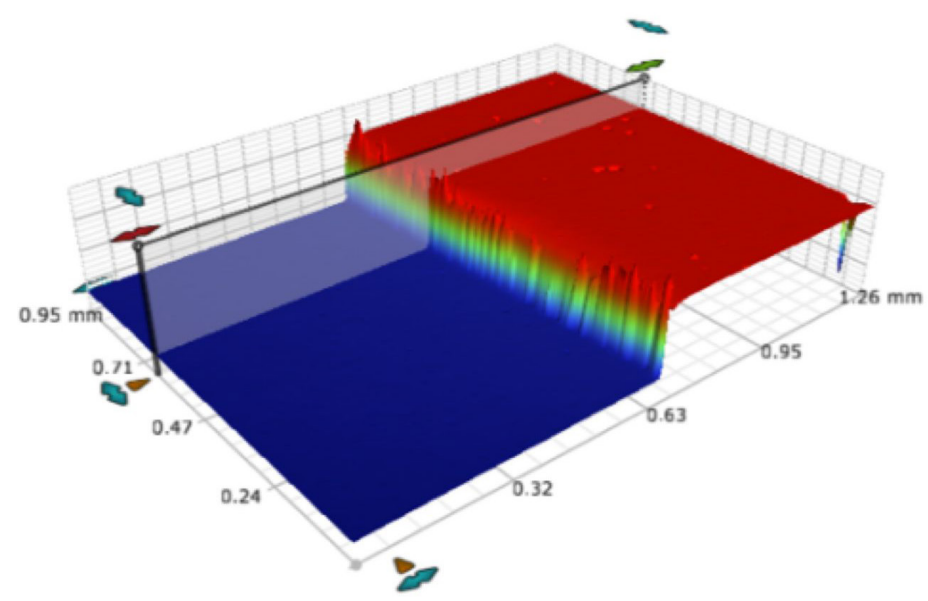

Figure 4. Example of 3D profilometer image of coating (Ti,Al,Si)N 


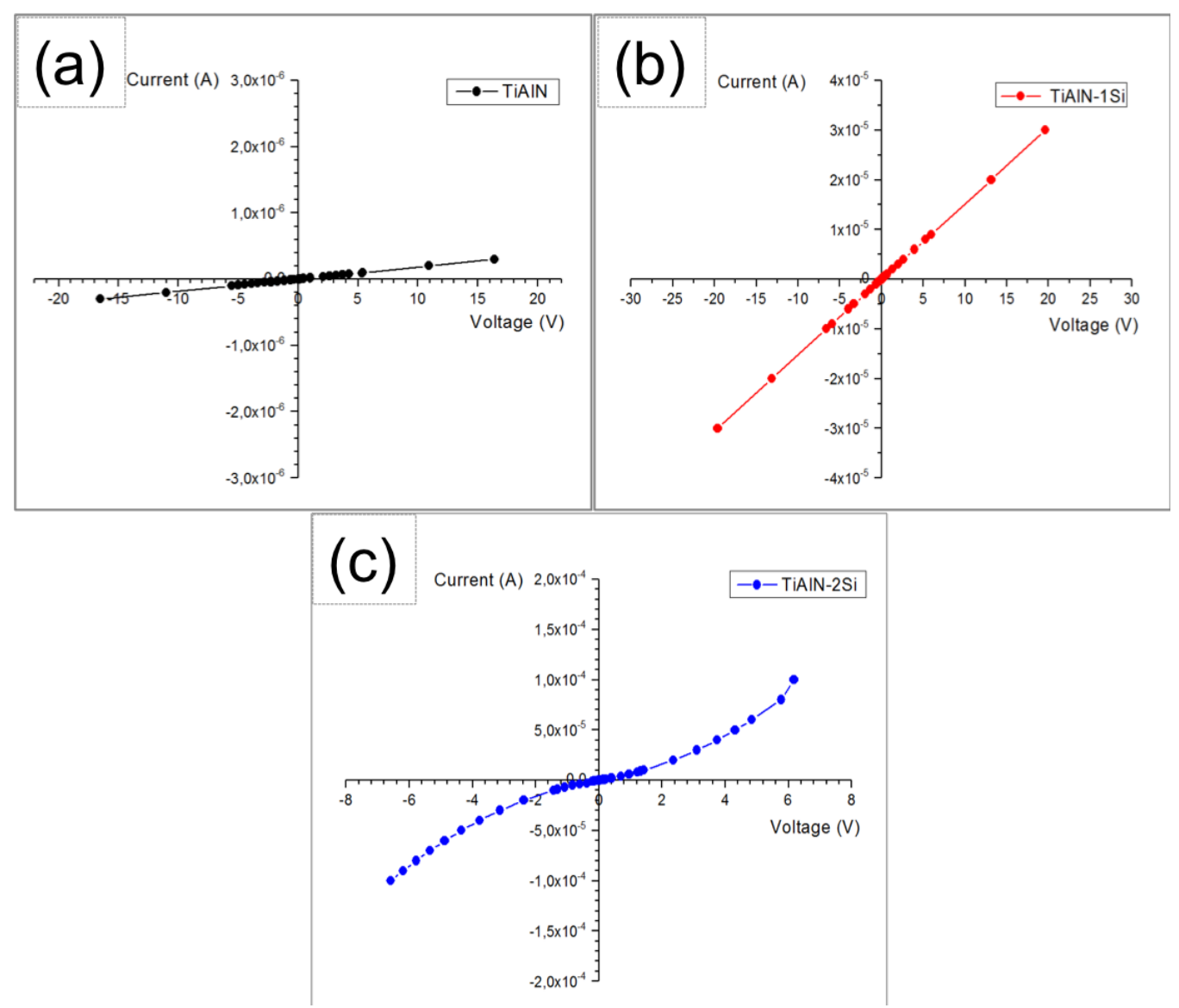

Figure 5. Current vs voltage of the (Al,Ti,Si)N films deposited on common glass (a) without Si, (b) 1 piece of Si and c- $2 \mathrm{Si}$.
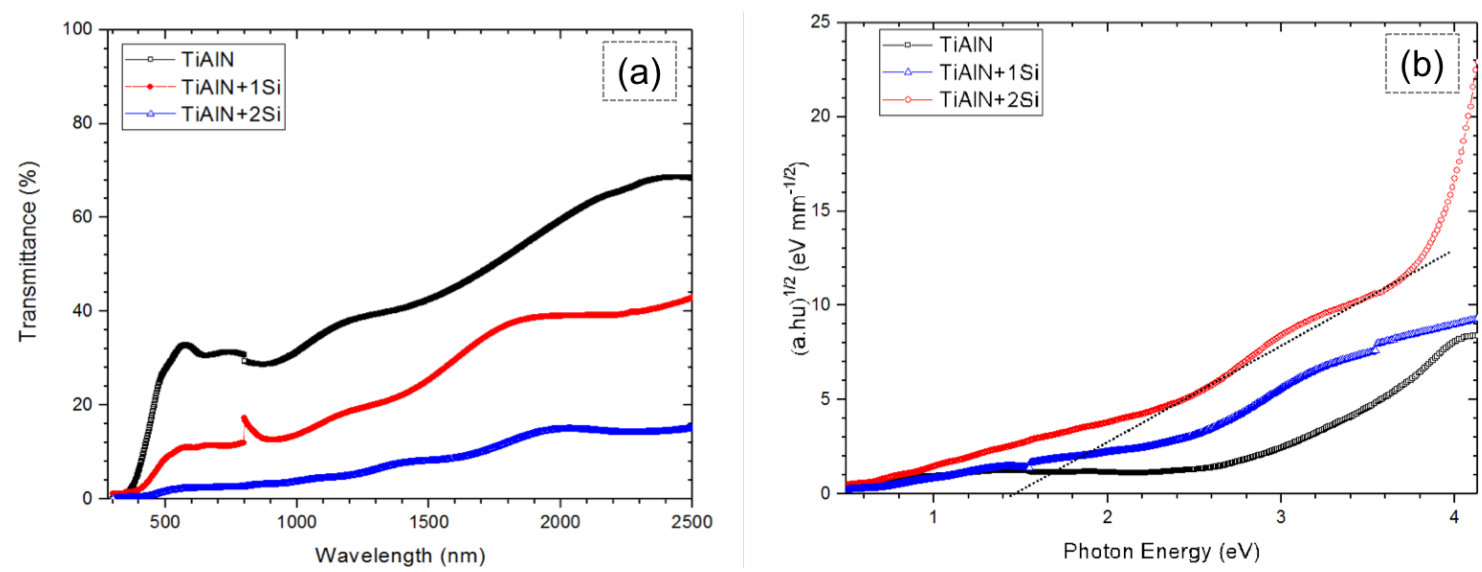

Figure 6. (a) Transmittance as a function of wavelength and (b) $(\alpha h v)^{1 / 2}$ Vs photon energy of the (Al,Ti,Si)N films deposited on common glass, taking as study parameter the Si content.

The Tauc model is the most used to calculate the optical gap of an amorphous semiconductor. Assuming that conduction and valence bands obey a square root-distributions, an extrapolation of $(\alpha h v)^{1 / 2}$ to the horizontal axis defines the energy gap (Eg indirect gap), observed in amorphous semiconductors $\mathrm{s}^{37}$. Figure 6b shows a determination of this Tauc gap; a dotted line represents these extrapolations, reaching a value of $1.5 \mathrm{eV}$. This result is in agreement with the physical process, because the optical gap energy must be higher than the electrical gap energy. The Tauc model suggests that the mean energy gap should be used as a measure of the optical gap associated with an amorphous semiconductor, and that it is directly related to a parameter that characterizes physically reasonable distributions of electronic states ${ }^{37}$.

The results discussed evidence shows that the silicon incorporated in the crystallographic lattice of TiAlN films 
determined drastically the physical properties of them, since the their structure crystalline change to amorphous and the electrical behavior shows changes the ceramic material to semiconductor material.

\section{Conclusions}

This paper presents a study on the effects of Si addition on structural, electrical, and optical properties of c/w-(Al,Ti) $\mathrm{N}$ films, where Si plays a role both as a substitutional solid solution and as in the formation of amorphous coatings. These structural changes modified the electrical and optical properties of the films since these change their electrical properties of ceramics to semiconductors. Additionally, the results show that the transmittance decreases when the Si content increases.

The electrical behavior make it possible to think of using these films as potential solar cells, since their energy gap is low.

\section{Acknowledgments}

The authors would like to acknowledge the financial support of División de Investigación y Extension of Universidad Nacional de Colombia (DIEB) through Project 35939.

\section{References}

1. Biró D, Papp S, Jakab-farkas L. Microstructural modification of (Ti 1-x Al x Si y) $\mathrm{N}$ thin film coatings as a function of nitrogen concentration. Acta Universitatis Sapientiae Electrical and Mechanical Engineering. 2010;2:146-58.

2. Panjan P, Miha Č. The influence of growth defects in sputterdeposited TiAlN hard coatings on their tribological behavior. Surf Coat Tech. 2016;288:171-8.

3. Ravankhah M, Savaloni H. Influence of deposition angle on the structural, morphological and optical properties of sputtered AlN thin films. Optik (Stuttg). http://dx.doi.org/10.1016/j. ijleo.2016.12.067.

4. Heim D, Hochreiter R. TiAlN and TiAlCN deposition in an industrial PaCVD-plant. Surf Coat Tech. 1998;98:1553-6.

5. Andrade MFC, Martinho RP, Silva FJG, Alexandre RJD, Baptista APM. Influence of the abrasive particles size in the micro-abrasion wear tests of TiAlSiN thin coatings. Wear. 2009;267:12-8.

6. Deng Y, Tan C, Wang Y, Chen L, Cai P, Kuang T. Effects of tailored nitriding layers on comprehensive properties of duplex plasma-treated AlTiN coatings. Ceram Int. 2017;43:8721-9.

7. Mwema FM, Akinlabi ET, Oladijo OP. A systematic review of magnetron sputtering of AlN thin films for extreme condition sensing. Materialstoday: Proceedings. 2020;26(pt 2):15461550 .

8. Chen L, Yang B, Xu Y, Pei F, Zhou L, Du Y. Improved thermal stability and oxidation resistance of $\mathrm{Al}-\mathrm{Ti}-\mathrm{N}$ coating by Si addition. Thin Solid Films. 2014;556:369-75.

9. Wang SQ, Chen L, Yang B, Chang KK, Du Y, Li J, et al. Effect of $\mathrm{Si}$ addition on microstructure and mechanical properties of Ti-Al-N coating. Int J Refract Met Hard Mater. 2010;28:5936.

10. Feng J, Zhang S, Lu Y, Yu H, Kang L, Wang X, et al. The spectral selective absorbing characteristics and thermal stability of SS/TiAlN/TiAlSiN/Si3N4 tandem absorber prepared by magnetron sputtering. Sol Energy. 2015;111:350-6.

11. Rebouta L, Capela P, Andritschky M, Matilainen A, Santilli P, Pischow K, et al. Characterization of TiAlSiN/TiAlSiON/ $\mathrm{SiO} 2$ optical stack designed by modelling calculations for solar selective applications. Sol Energy Mater Sol Cells. 2012;105:202-7.

12. Wattoo AG, Xu C, Yang L, Ni C, Yu C, Nie X, et al. Design, fabrication and thermal stability of spectrally selective TiAlN/ SiO2 tandem absorber. Sol Energy. 2016;138:1-9.

13. Prieto G, Borja E, Olaya JJ. Effect of Ni content on the optical and electrical properties of $\mathrm{ZrTiSiNiN}$ thin films deposited by co-sputtering. Rev Acad Colomb Cienc Exactas Fis Nat. 2019;43:366-74.

14. Liu CC, Huang JL. Effect of the electrical discharge machining on strength and reliability of TiN/Si3N4 composites. Ceram Int. 2003;29:679-87.

15. Lotsch FHK, Asakura EBT, Kamiya T, Monemar B, Venghaus $\mathrm{H}$, Weinfurter $\mathrm{H}$, et al. Transition metal carbides, nitrides and oxides. New York: Springer-Verlag; 2001.

16. Flink A. Growth and characterization of Ti-Si-N hard coatings [dissertation]. Sweden: Linköping Studies in Science and Technology; 2006.

17. Zivkovic L, Nikolic Z, Boskovic S, Miljkovic M. Microstructural characterization and computer simulation of conductivity in Si3N4-TiN composites. J Alloys Compd. 2004;373:231-6.

18. Lux F. Models proposed to explain the electrical conductivity of mixtures made of conductive and insulating materials. $\mathrm{J}$ Mater Sci. 1993;28:285-301.

19. Veprek S, Veprek-Heijman MGJ, Karvankova P, Prochazka J. Different approaches to superhard coatings and nanocomposites. Thin Solid Films. 2005;476:1-29.

20. Chen YI, Chang SC, Chang LC. Oxidation resistance and mechanical properties of $\mathrm{Zr}-\mathrm{Si}-\mathrm{N}$ coatings with cyclic gradient concentration. Surf Coat Tech. 2017;320:168-73.

21. Choi H, Jang J, Zhang T, Kim JH, Park IW, Kim KH. Effect of $\mathrm{Si}$ addition on the microstructure, mechanical properties and tribological properties of $\mathrm{Zr}-\mathrm{Si}-\mathrm{N}$ nanocomposite coatings deposited by a hybrid coating system. Surf Coat Tech. 2014;259:707-13.

22. Martin PJ, Bendavid A, Cairney JM, Hoffman M. Nanocomposite Ti-Si-N, Zr-Si-N, Ti-Al-Si-N, Ti-Al-V-Si-N thin film coatings deposited by vacuum arc deposition. Surf Coat Tech. 2005;200(7):2228-35.

23. Musil J, Daniel R, Zeman P, Takai O. Structure and properties of magnetron sputtered $\mathrm{Zr}-\mathrm{Si}-\mathrm{N}$ films with a high ( $\geq 25$ at.\%) Si content. Thin Solid Films. 2005;478(1-2):238-47.

24. Musil J. Hard nanocomposite coatings: thermal stability, oxidation resistance and toughness. Surf Coat Tech. 2012;207:50-65.

25. Ferreira CP, Castro MMR, Tentardini EK, Lins VFC, Saliba PA. Silicon influence on corrosion resistance of magnetron sputtered $\mathrm{ZrN}$ and $\mathrm{ZrSiN}$ thin films. Surf Eng. 2018;0(0):1-8.

26. Dang C, Li J, Wang Y, Yang Y, Wang Y, Chen J. Influence of $\mathrm{Ag}$ contents on structure and tribological properties of TiSiN-Ag nanocomposite coatings on Ti-6Al-4V. Appl Surf Sci. 2017;394:613-24.

27. Materials Project [homepage on the Internet]. 2018 [cited 2018 Nov 14]. Available from: https://materialsproject.org

28. Petrman V, Houska J. Trends in formation energies and elastic moduli of ternary and quaternary transition metal nitrides. $\mathrm{J}$ Mater Sci. 2013;48:7642-51

29. Zauner L, Ertelthaler P, Wojcik T, Bolvardi H, Kolozsvári $\mathrm{S}$, Mayrhofer PH, et al. Reactive HiPIMS deposition of TiAl-N: influence of the deposition parameters on the cubic to hexagonal phase transition. Surf Coat Tech. 2020;382:125007.

30. Feng C, Zhu S, Li M, Xin L, Wang F. Effects of incorporation of $\mathrm{Si}$ or Hf on the microstructure and mechanical properties of Ti-Al-N films prepared by arc ion plating (AIP). Surf Coat Tech. 2008;202:3257-62.

31. Hapert JJV. Hopping conduction and chemical structure: a study on silicon suboxides [dissertation]. Utrecht: Universiteit Utrecht. 
32. Miletić A, Panjan P, Škorić B, Čekada M, Dražič G, Kovač J. Microstructure and mechanical properties of nanostructured Ti-Al-Si-N coatings deposited by magnetron sputtering. Surf Coat Tech. 2014;241:105-11.

33. Yu D, Wang C, Cheng X, Zhang F. Microstructure and properties of TiAlSiN coatings prepared by hybrid PVD technology. Thin Solid Films. 2009;517:4950-5.

34. Signore MA, Taurino A, Valerini D, Rizzo A, Farella I, Catalano $\mathrm{M}$, et al. Role of oxygen contaminant on the physical properties of sputtered AlN thin films. J Alloys Compd. 2015;649:126772.
35. Bozhko I, Rybalko E, Pershukova A, Fedorischeva M, Khristenko Y, Sergeev V. Microstructure and properties of nanocomposite Al-Si-N system coatings produced by magnetron sputtering. AIP Conf Proc. 2016;1772:030014.

36. O'Leary SK, Lim PK. On determining the optical gap associated with an amorphous semiconductor: a generalization of the Tauc model. Solid State Commun. 1997;104:7-21.

37. Dolgonos A, Mason TO, Poeppelmeier KR. Direct optical band gap measurement in polycrystalline semiconductors: A critical look at the Tauc method. J Solid State Chem. 2016;240:43-8. 